\title{
Potential relationship between postoperative indocyanine green elimination measurement and coagulation profile in patients undergoing major liver surgery. Preliminary results.
}

\author{
Ll.Alarcón Pérez, P. Bono Chaure, J. Narváez Salazar, L. Olmedilla, JM Pérez-Peña, P. Duque González. \\ Hospital General Universitario Gregorio Marañón, Madrid
}

Background and Goal of Study:

Indocyanine green elimination by pulse spectrophotometry is a non-invasive liver function monitoring system. Thromboelastometry is a global coagulation test. The aim of this study is to assess the relationship between postoperative ICG plasma disappearance rate (ICG PDR \% $\mathrm{min}$ ) and thromboelastometric parameters, procoagulant and anticoagulant protein levels following major liver surgery.

\section{Materials and Methods:}

This study is registered in ClinicalTrials.gov under the number NCT02813538.

22 patients scheduled for mayor liver resection were selected.

ICG PDR, thromboelastometric analysis (coagulation time (CT), maximum clot firmness (MCF) and maximum lysis (ML) in EXTEM, INTEM and FIBTEM), procoagulant (Factor II, V, VII, VIII, IX, X, XI and XII) and anticoagulant factors (protein $\mathrm{C}$, protein $\mathrm{S}$ and antithrombin III) were measured preoperatively and on postoperative day 1 and 2 .

\section{Results and Discussion:}

The mean ICG PDR was 17.2 \pm 7.7 preoperatively, $16.96 \pm 7.75$ on postoperative day 1 and $16.24 \pm 7.91$ on postoperative day 2 .

The thromboelastometric mean values remained within the normal range. Significant correlation were found between ICG PDR and $\mathrm{CT}_{\text {EXTEM }}$ $(\mathrm{r}=-0,52, \mathrm{p}=0.014), \mathrm{MCF}_{\text {EXTEM }}(\mathrm{r}=-0,49, \mathrm{p}=0.021)$ and protein $\mathrm{C}$ levels $(\mathrm{r}=0,46, \mathrm{p}=0.036)$ measured on postoperative day 1 . This significant correlation persist on postoperative day 2 only between ICG PDR and protein $C$ levels $(r=0,72, p=0.001)$.

We have not found any significant correlation between ICG PDR and procoagulant protein levels or routine coagulation tests.
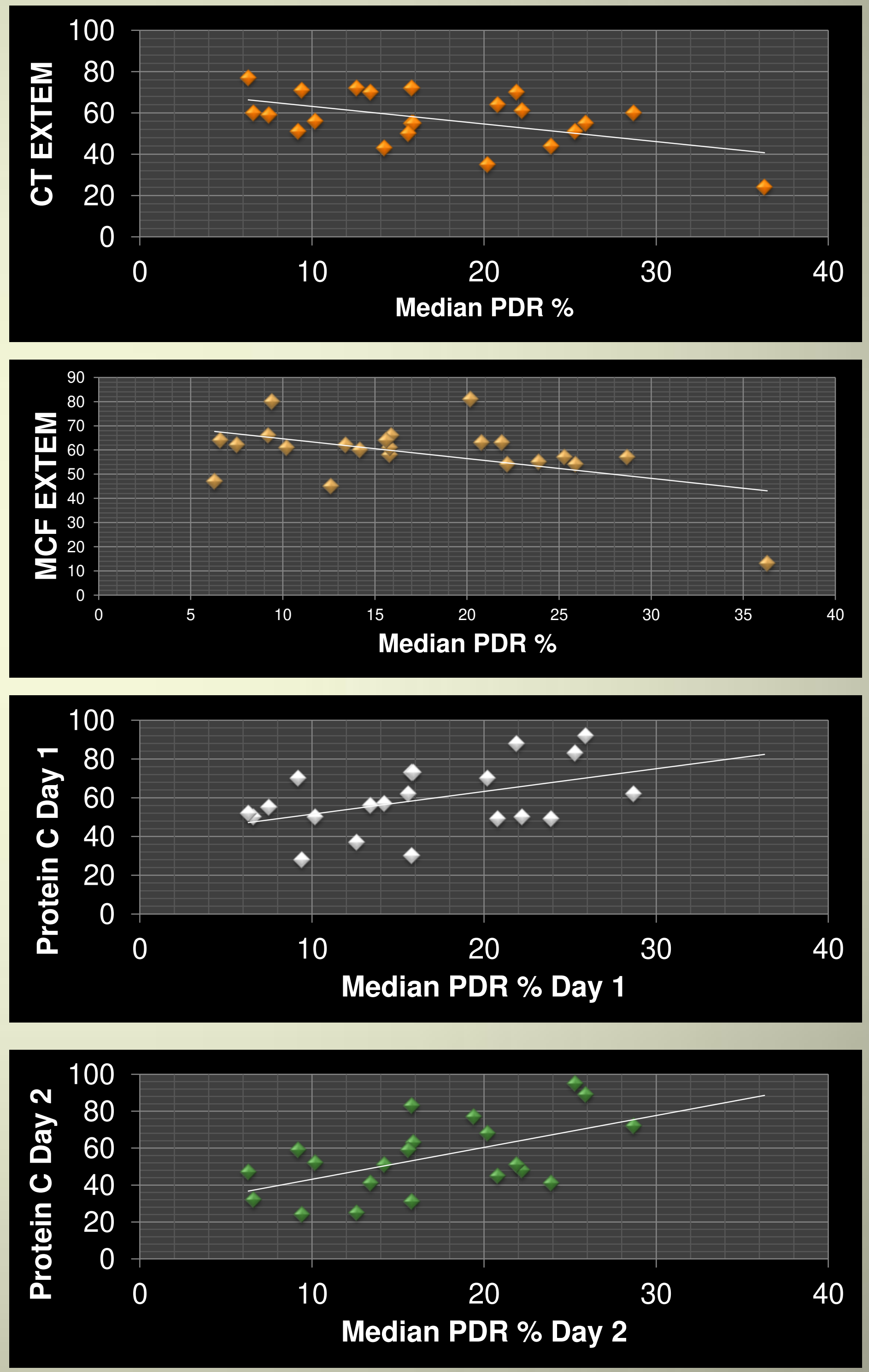

\section{Conclusions:}

ICG PDR measured by pulse spectrophotometry is a non-invasive liver function test in patients undergoing major liver resection. Taken ICG PDR as index of severity, CT and MCF measured in EXTEM might be a suitable prognostic factor. Protein $\mathrm{C}$ is a pivotal anticoagulant factor synthesized in liver known to be dramatically decreased following major hepatic surgery. Our results suggest that early postoperative protein $\mathrm{C}$ levels may be also prognostic of liver dysfunction. 